\title{
ESTUDIOS DE LÍNEA BASE EN CAPTACIÓN \\ DE SEMILLA, CULTIVO Y PERLICULTURA EN LA OSTRA \\ Perlera alada Pteria Sterna (GoUld 1851) \\ en la costa de Piura, Perú
}

\author{
Daniel Rojas Hurtado* \\ https://orcid.org/0000-0001-9589-8308 \\ Universidad Nacional Agraria La Molina, Perú \\ MARIo MONTEForte SÁnCHEZ \\ https://orcid.org/0000-0002-2893-6498 \\ Regina Machado BazalaR \\ https://orcid.org/0000-0002-4211-0326 \\ Universidad Nacional Agraria La Molina, Perú \\ Fernando Alexis Fernandini Valdez \\ https://orcid.org/0000-0002-8049-6020 \\ Universidad Nacional Agraria La Molina, Perú
}

Centro de Investigaciones Biológicas del Noroeste S.C. (CIBNOR). La Paz BCS, México

Recibido: 13 de agosto del 2020 / Aprobado: 16 de noviembre del 2020

doi: https://doi.org/10.26439/ing.ind2021.n40.5148

RESUMEN: Entre 2017 y 2018, se realizaron experimentos de cultivo extensivo y perlicultura con la ostra perlera alada Panámica, Pteria sterna (Bivalvia: Pteriidae), en la costa de Los Órganos y Cabo Blanco (Piura, Perú). Se evaluaron tres objetivos simultáneos: eficiencia de colectores en la captación de semilla (sitios y profundidad), cría en dos tipos de artefacto (supervivencia y crecimiento) y ensayos de perlicultura por implante (Mabe) y cirugía (perla libre). Los resultados demostraron la factibilidad de impulsar el desarrollo comunitario de granjas perleras en la región.

PALABRAS CLAVE: Pteria sterna / captación de semilla / cultivo extensivo / perlicultura / extensionismo integral

\footnotetext{
*Correo electrónico: danielrojas@lamolina.edu.pe
} 


\section{BASELINE STUDIES ON SPAT COLLECTION, OFFSHORE CULTURE AND PEARL CULTURE OF WINGED PEARL OYSTER PTERIA STERNA (GOULD 1851) ON THE COAST OF PIURA, PERU}

ABSTRACT: Between 2017 and 2018, extensive cultivation and pearl culture experiments were carried out with the Panamic winged pearl oyster Pteria sterna (Bivalvia: Pteriidae) on the coast of Los Órganos and Cabo Blanco (Piura, Peru). Three objectives were evaluated in sequential phases: collectors' spat collection efficiency (sites and depth), offshore cultivation in two types of artifacts (survival and growth), and trials on pearl culture by implantation (Mabe) and surgical (free pearl) techniques. The results demonstrated the feasibility of promoting community development of pearl farms in the region.

KEYWORDS: Pteria sterna / spat collection / extensive culture / pearl culture / integral outreach 


\section{INTRODUCCIÓN}

El cultivo extensivo de moluscos bivalvos se fundamenta en la captación de semilla salvaje en la columna de agua mediante colectores artificiales, prosiguiendo las etapas de cría en mar con artefactos contenedores (bolsas, charolas, canastas, carteras, linternas, sartas, etc.) que se colocan en sistemas suspendidos o sobre piso (fondo o zonas de marea) hasta la talla/edad de cosecha. En la actualidad, la producción comercial de muchas especies con valor gourmet combina el cultivo extensivo con el semiextensivo (recibe semilla producida en laboratorio), el cual paulatinamente gana terreno en número de especies incorporadas y volumen de producción (Organización de las Naciones Unidas para la Alimentación y la Agricultura [FAO], 2020).

Ese modelo no difiere en mucho al de las granjas de ostras perleras, pero se dirige al mercado de la joyería con nácar y perlas cultivadas. Sin embargo, el progreso tecnológico hacia el siglo xxı ha impelido transformaciones sustanciales en la planificación y operación de una granja perlera (Monteforte y Cariño, 2013; Johnston, Hine y Southgate, 2018), viendo que no cesa el interés por la perlería en otros países y sus especies tanto de Pinctada como del género análogo, Pteria. Estas últimas son conocidas como ostras perleras aladas y son fáciles de distinguir a vista por dicha característica, así como por la forma ovoide alargada con valvas de curvatura moderadamente asimétrica. En los últimos años, ha crecido la producción de semilla en laboratorio a escala comercial de madreperlas chicas ( $P$. martensi, $P$. fucata, $P$. chemnitzii), igualmente, se nota en especies grandes como $P$. margaritifera y en las gigantes de los respectivos géneros, P. maxima y Pt. penguin (Southgate, 2008). De hecho, la clasificación por tamaño establece una regionalización global en función de las especies presentes y el tamaño de perlas que pueden producir (Taylor y Strack, 2008; Monteforte y Cariño, 2013). Por ejemplo, dos especies grandes (P. mazatlanica y Pt. sterna) habitan en la Provincia Panámica, y en la zona del Caribe-Antillas están P. imbricata y Pt. colymbus que son especies chicas.

En sí, la finalidad de una granja perlera es proveer un número rentable y constante de ostras adultas aptas para recibir operaciones de perlicultura', es decir, la producción de perlas cultivadas mediante técnicas de implante (media-perla o Mabe) y de cirugía (perla libre) (Alagarswami y Dharmaraj, 1984; Haws, C. S. Ellis y P. E. Ellis, 2006; Taylor y Strack, 2008; Monteforte, 2013a). La evidencia muestra que el desarrollo de la industria comporta una historia de adaptaciones y mejoras sobre tecnologías, relativamente, similares, si bien es frecuente que cada granja desarrolle innovaciones propias (Southgate, 2008; Monteforte, 2013b). No obstante, es indispensable calibrar los indicadores

1 Por restricciones de espacio, para saber más acerca de los métodos y técnicas empleados en la producción inducida de perlas (perlicultura), remitimos al lector a las cuatro referencias base apuntadas, disponibles en internet. También en ese medio hay un rico acervo de videos y documentales donde se puede explorar con lujo de detalle esta temática. 
bioecológicos de la(s) especie(s) objetivo en función de las condiciones reales que ofrezca algún sitio planteado, las cuales definirán la periodicidad y duración de las etapas de cría, la arquitectura de sistemas y artes de cultivo, los criterios para hallar sitios propicios, las rutinas de mantenimiento y monitoreo y las épocas de perlicultura, entre otras variables operativas. Naturalmente, el estado de la población natural -en especial, su potencial de reclutamiento- es el factor clave en la factibilidad integral de un proyecto perlero (o con un bivalvo gourmet en tal caso) en modalidad de extensivo y, por lo tanto, se debe examinar en prioridad mediante experimentos de captación de semilla.

En este trabajo se presenta un análisis técnico-operativo de las acciones que se llevan a cabo en el Perú desde 2017 para promover la instalación de granjas perleras con Pt. sterna, conocida localmente como concha perla o concha perlera. Los estudios se centraron en la zona norte, específicamente, en la provincia de Talara, involucrando especialistas del sector académico, entidades del Gobierno y privadas, y comunidades en la región, siendo Los Órganos y Cabo Blanco el demostrativo social del proyecto (FloresYsla, Rojas-Hurtado y Fernandini, 27 de septiembre de 2017; AgroMar del Pacífico, 2018). En este texto examinaremos los resultados de los experimentos simultáneos concernientes a la respuesta de Pt. sterna ante estrategias de manejo en la modalidad de cultivo extensivo. La información generada en esta área geográfica, que es nueva en la perlería global, tiene relevancia en el marco oceanográfico y biogeográfico de la especie por su valor comparativo respecto al golfo de California y la contracosta de la península de Baja California en el océano Pacífico, y otros sitios al sur donde se cuenta con datos útiles. El presente trabajo incluye resultados de las primeras sesiones de perlicultura y comentarios respecto al aprendizaje por los grupos objetivo en la comunidad.

\section{MARCO DEL ESTUDIO}

\subsection{Medio ambiente}

En el mar del Perú confluye la peculiar batimetría de la región con una compleja circulación de masas de agua y corrientes, dando lugar a una de las más importantes e intensas extensiones de afloramiento (surgencia) en el mundo-océano (Echevin, Aumont, Ledesma y Flores, 2008; Morón Antonio y Tenorio, 2011). Es así como a este mar se le reconoce por ser uno de los más productivos para la pesca comercial y en corolario esas condiciones promueven una alta concentración de fitoplancton y nutrientes que benefician a las granjas de moluscos bivalvos. De allí la representación de los dos recursos bandera respectivos, la anchoveta (Engraulis ringens) y la escalopa púrpura o concha abanico (Argopecten purpuratus) (Ramírez-Gastón, Sandoval-Méndez y Vicente-Cárdenas, 2018), junto a una rica biodiversidad en las aguas costeras. Además, la región recibe períodos de El Niño (calentamiento) y La Niña (enfriamiento) que provocan cambios drásticos en las condiciones oceanográficas y sus parámetros clave, como temperatura y nutrientes, 
entre otros (Paredes et al., 1998; Swartzman, Bertrand, Gutiérrez, Bertrand y Vásquez, 2008; Morón Antonio y Tenorio, 2011).

En la fauna marina y costera, estas variaciones pueden acortar o alargar el límite sur de la Provincia Panámica, con lo cual el mar peruano se comporta como una zona de transición tropical-subtropical que en ocasiones se detecta hasta el tercio norte de la costa de Chile (Álamo y Valdivieso, 1997; Paredes et al., 1998). Esta situación se asemeja a lo que Lluch-Belda (2000) definió como centro de actividad biológica (BAC, por sus siglas en inglés), correspondiente a la plataforma continental y zona costera en el occidente de Baja California Sur (México), en particular, la región del golfo de Ulloa y los grandes sistemas lagunares (p. ej., San Ignacio, Boca de Santo Domingo y el complejo MagdalenaAlmejas), donde se encuentran poblaciones de Pt. sterna bien asentadas (Keen, 1971, y observaciones personales de M. Monteforte).

La zona de Piura-Tumbes juega un papel importante en esta dinámica porque representa el emplazamiento poblacional estable más sureño para numerosas especies de peces e invertebrados de esa provincia faunística; tal es el caso de la ostra perlera Pt. sterna (Keen, 1971; Álamo y Valdivieso, 1997; Ordinola et al., 2010). En efecto, las características particulares de clima y masas de agua en la costa del Perú han creado una suerte de ecotono variable en su posición y/o rango de efecto que es prácticamente constante, con parámetros oceanográficos cuyos valores suelen ser distintos entre el espacio norte y el del sur, aún en la misma época del año y a corta distancia (Echevin et al., 2008; Swartzman et al., 2008; Morón Antonio y Tenorio, 2011; Vergara et al., 2016). Estas condiciones confieren alta pertinencia a la instalación de cultivos extensivos en la región, ya que esta modalidad depende de la estacionalidad reproductiva, así como de los rangos de parámetros clave en el agua que pueden afectar, positiva o negativamente, en la eficiencia de la captación de semilla y en el desarrollo de los animales durante la cría.

\subsection{Antecedentes científicos y técnicos}

Debido a convergencias históricas, en el golfo de California, particularmente en bahía de La Paz (Baja California Sur, México), se ha concentrado el mayor acervo de conocimiento científico y tecnológico disponible para P. mazatlanica y Pt. sterna (Monteforte y Cariño, en prensa). Esta última especie ha recibido mayor atención en los últimos años, tanto en el ámbito académico como el comercial, por su novedad en el mercado mundial y la exclusiva cromática de su nácar. Las dos empresas perleras actuales, ambas en el golfo de California (Perlas del Mar de Cortez desde 1996 en Guaymas, Sonora, y Perlas del Cortez fundada en La Paz en 2001, renovada recientemente) cultivan esta especie en modalidad de extensivo y utilizan dicho distintivo en sus estrategias de venta. La empresa de Guaymas ha sabido explotar exitosamente la primicia de la perla libre; mientras en La Paz, cuya producción hasta ahora se limita a perlas Mabe y joyería, se ha diversificado a productos cosméticos. 
Los estudios fuera de esta región son puntuales, hechos en Costa Rica (Solano López, Cabrera Peña, Protti Quesada y Cruz Soto, 1995; Solano López, Cabrera Peña, Palacios y Cruz, 1997a, Solano López, Cabrera Peña, Cruz y Palacios, 1997b) y Panamá (Cipriani Guzmán y López, 2008), y se concentran en conocer la biología y ecología de las poblaciones de $P$. mazatlanica. Además, parece evidente que la captación de semilla de esta especie ha sido históricamente baja en los sitios donde se ha probado (Monteforte, 2013b).

En 2013, el gremio perlero mexicano consiguió instaurar una normatividad gubernamental para el cultivo y la perlicultura comercial de las cuatro especies de ostras perleras presentes en el litoral de México, que comprende los dos grandes mencionados en el golfo de California, y P. imbricata y Pt. colymbus, las dos pequeñas de la región Caribe-Antillas (Secretaría de Agricultura, Ganadería, Desarrollo Rural, Pesca y Alimentación, 2013). En el Ecuador, últimamente, se ha definido otro polo de certificación científica y técnica para Pt. sterna, con especial énfasis en estudios sobre la producción de perlas Mabe (p. ej., Lodeiros et al., 2018; Gregori et al., 2019; Freites et al., 2020; Jara et al., 2020). Por el contrario, en el Perú se conoce poco del potencial perlero salvo por datos históricos de pesquería comercial de Pt. sterna, que siempre fue de baja captura y por poco tiempo (Murphy, 1923; Baudin, 1961). Luque Sánchez, Solís Acosta, Morón Antonio y Crispín Carpio (2001) describieron una pesquería esporádica de la especie hasta 1999, principalmente, con fines artesanales y consumo humano, reportando intensa extracción comercial en su momento frente a la costa de Piura por flotas marisqueras.

En todo caso, solo hasta los últimos 10-15 años algunos investigadores en el Instituto del Mar de Perú (IMARPE) y universidades con línea de ciencias marinas han dedicado estudios en Pt. Sterna, pero han sido escasos, discontinuos y, mayormente, enfocados en las poblaciones naturales y oceanografías con fines de manejo pesquero, aunque sin perder de vista la perlería (Luque Sánchez et al., 2001; Ordinola et al., 2010). En particular, Ordinola, Alemán y Vera (2013), examinaron el perfil bioecológico de una colonia aglomerada de Pt. sterna que hallaron sobre una red a la deriva; y se destaca una tesis de maestría por Treviño Zambrano (2018) quien estudió la respuesta de individuos recolectados ante tratamientos de maduración y desove en condiciones de laboratorio.

Las observaciones en el Perú muestran que la población natural de Pt. sterna es abundante en todas las clases de talla (plataformas petroleras, postes de muelles, boyas y objetos sumergidos, artes de cultivo de concha abanico, hasta en la carena de embarcaciones); los animales exhiben conchas robustas y bien ornamentadas, biso grueso y fuerte, y los grandes son vigorosos y muy grandes, tanto los silvestres como los cultivados. Llamó la atención su alta resistencia a tiempos de exposición bajo 
anestesia, desecación y a manipulaciones, en general. En cuanto a la cromática del nácar, la banda marginal es ancha con tonos predominantes de esmeralda, bronce y lila/violeta, dentro del patrón de la especie.

\section{DISEÑO EXPERIMENTAL Y METODOLOGÍA}

Los experimentos con Pt. sterna apuntaron a tres objetivos simultáneos y de cortomediano plazo de acuerdo con los lineamientos del Proyecto SNIP 162711. Tales objetivos fueron los siguientes: a) evaluar la captación de semilla en dos tipos de células recolectoras y dos sitios hasta $6 \mathrm{~m}$ de profundidad; b) evaluar supervivencia y crecimiento de un grupo testigo de juveniles en dos artes para cultivo en suspensión (un sitio) durante 7 meses, y c) formar un grupo de técnicos perleros, particularmente, en la cirugía de perla libre, y monitorear el desempeño de su aprendizaje. Es necesario señalar que los grupos experimentales estudiados en el segundo y tercer objetivo provienen de una recolecta de individuos epibiontes que abundan en las artes de cultivo de $A$. purpuratus (Flores-Ysla et al., 27 de septiembre de 2017; AgroMar del Pacífico, 2018).

La cría de estos animales transcurrió en el módulo piloto de AgroMar del Pacífico en Los Órganos (figura 1) y para el presente estudio se consideraron tres grupos de talla, tomando la altura de la concha (eje dorso-ventral) como referencia: chica (20-40 $\mathrm{mm}$ ), mediana (40-60 $\mathrm{mm}$ ) y grande (70 $\mathrm{mm}$ y mayores). Esto bajo la premisa de que los granjeros de la concha abanico acostumbran a limpiar los artefactos cada 3-4 meses. Los individuos más grandes de este lote $(>100 \mathrm{~mm}$ de alto, casi la mitad en stock, con 11-12 meses transcurridos en cultivo), se utilizaron en jornadas prácticas de perlicultura abiertas al público y en el entrenamiento de aprendices seleccionados en estas jornadas.

\section{1 Área de estudio}

Sistemas de captación de semilla y cultivo en suspensión se instalaron en el área de concesión de AgroMar del Pacífico en Los Órganos y en Cabo Blanco (figura 1). En esta selección se tomaron en cuenta criterios de factibilidad operativa por AgroMar del Pacífico y la cercanía a Cabo Blanco donde se ejecutó el demostrativo social del presente proyecto. 

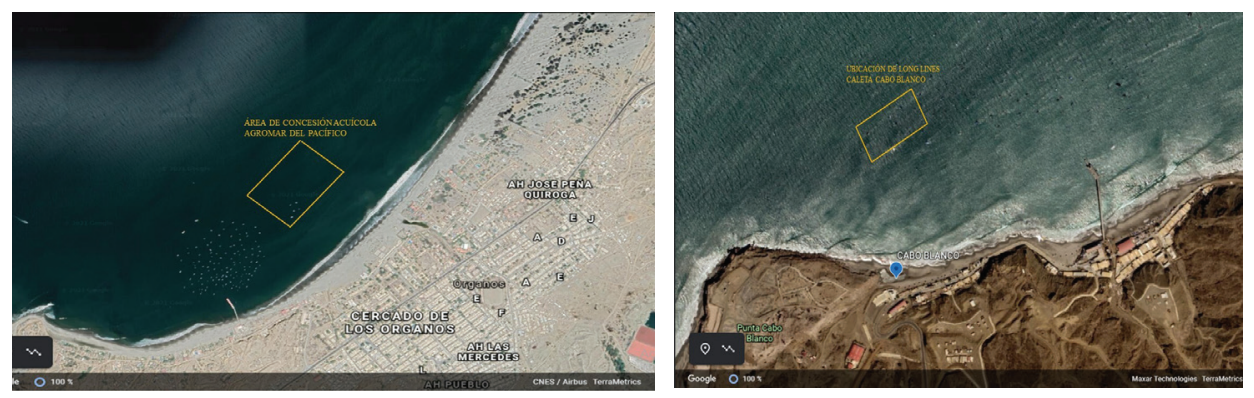

Figura 1. Zona de Los Órganos, coordenadas: 4¹0'04"S y 8107'53"O (1a). Zona de Cabo Blanco,

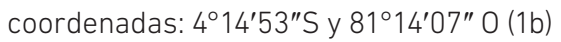

Fuente: Google Earth (2016)

\subsection{Captación de semilla}

Para la evaluación de la abundancia en la captación de semilla, se instaló un sistema long-line de 50 m de longitud en Los Órganos y otro en Cabo Blanco, en cada sitio se probaron, simultáneamente, dos tipos de células colectoras: unas con substrato de fijación de malla Netlon azul envueltas en bolsa de malla nailon color verde con 1,5 mm de luz; otras en costal cebollero color rojo envuelto en el mismo tipo de bolsa. Las primeras son de uso común para la captación de $A$. purpuratus. Estas células se amarraron en racimos conteniendo los dos tipos de células colectoras, las cuales se repartieron en 10 líneas verticales hasta $6 \mathrm{~m}$ de profundidad en cada sitio (figura 2). Los colectores permanecieron sumergidos durante 80 días, entre septiembre y noviembre de 2017; al cabo de los cuales fueron lavados (sacudido o "desgrane") en tinas llenas de agua marina, de donde se recuperaron las pequeñas conchas, registrando su repartición en las tres profundidades probadas en cada sitio. El tiempo de inmersión se estableció un tanto arbitrariamente procurando coincidir con la temporada fría "normal" en la costa del Perú. 


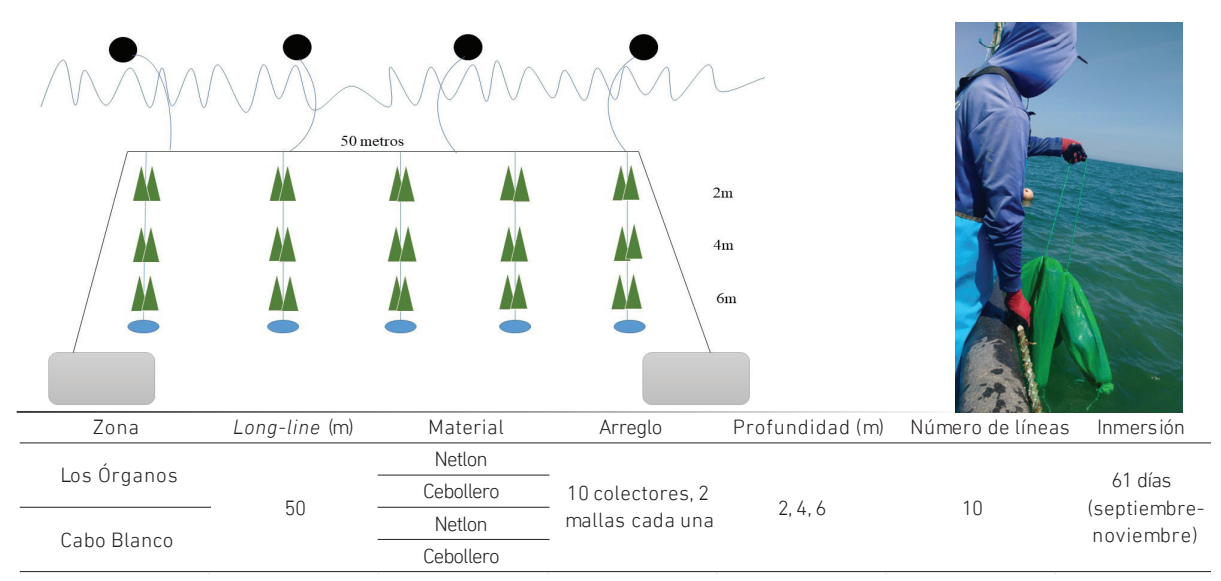

Figura 2. Sistema de captación de semilla de Pteria sterna colocado en Los Órganos y Cabo Blanco mostrando los detalles del diseño experimental

Elaboración propia

\subsection{Etapa de cría en campo}

Se usaron jaulas flexibles tipo linterna de tres pisos como las tradicionales para el cultivo de pectínidos y redes de cartera (pocket-nets) que son de uso común en las granjas de ostras perleras (figura 3). Los ejemplares utilizados para la siembra fueron provistos por el módulo piloto de AgroMar del Pacífico en Los Órganos. Los tres grupos de talla (chica, mediana y grande) se dividieron entre este módulo y el de Cabo Blanco; en el primero, se usaron linternas; en el segundo, las carteras. Con esas variables se analizó en cada sitio/artefacto el efecto de la densidad (número y repartición de individuos por artefacto) en comparativo a los grupos de talla (figura 3). El seguimiento por muestreo fue mensual durante siete meses, registrando la longitud y altura (en milímetros) de cada individuo en los lotes. La mortalidad sería registrada planeando sustituir las faltas por animales vivos con el fin de mantener densidades constantes en los artefactos. Sin embargo, el conteo mensual de muertos en los tres grupos siempre fue muy bajo y con alta frecuencia de ceros. 
$3 a$

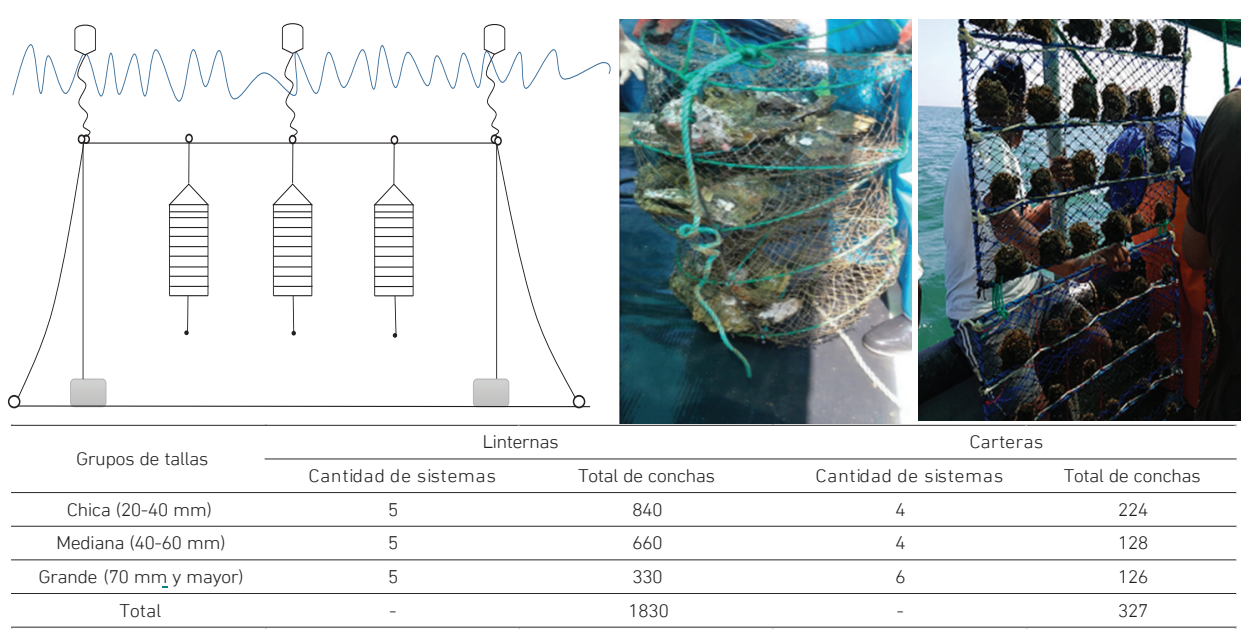

Figura 3. Diseño del sistema de cultivo en suspensión con long-line de $50 \mathrm{~m}$ de longitud (3a). Arreglo de linternas utilizadas en Los Órganos (3b). Arreglo de carteras en Cabo Blanco. Parte inferior de la figura se muestra el detalle de los experimentos realizados durante la etapa de cultivo tardío de Pteria sterna en Los Órganos con el arreglo experimental en linternas y en Cabo Blanco con el arreglo experimental en carteras (3c)

Elaboración propia

\subsection{Ensayos de perlicultura}

Entre septiembre y octubre de 2018, se realizaron dos jornadas de perlicultura abiertas al público en las cuales el grupo de AgroMar del Pacífico (el instructor y tres aprendices, directamente preparados) impartió prácticas de implante (Mabe o media-perla) y de cirugía (perla libre nucleada) siguiendo los métodos tradicionales para madreperla (Alagarswami y Dharmaraj, 1984; Haws et al., 2006; Taylor y Strack, 2008; Monteforte, 2013a) adaptados a Pt. sterna. Un total de 712 individuos producto de los experimentos de cultivo en el módulo piloto de Los Órganos, que a su vez fueron recolectados a mano en los sistemas de la concha abanico unos 12-13 meses antes (Flores-Ysla et al., 27 de septiembre de 2017), se seleccionaron entre los de mayor tamaño (100-120 mm de longitud de concha) y se dividieron en dos grupos: uno de 508 individuos para implantar media-esfera de plástico con diámetro variado entre 8 y $12 \mathrm{~mm}$; otro de 204 individuos para cirugía de perla libre con núcleos esféricos comerciales de 6,$8 ; 8,0$ y $9,3 \mathrm{~mm}$ de diámetro.

En esta ocasión se aplicó anestesia con Eugenol en dosis de $3 \mathrm{ml} / \mathrm{L}$ y con 5-7 min de exposición por lotes de 15-20 ostras a turnos, esto en el entendido de que dicha substancia no era del todo adecuada, pero no fue posible conseguir propileno de fenoxetol ni benzocaína pura como recomiendan algunos autores (Granados-Amores et al., 2018). 
Como pegamento para los implantes de Mabe se utilizó uno de tipo contacto, disponible en el comercio local. La adhesividad fue alta, pues pocos implantes se despegaron, pero al parecer era más volátil que otras resinas epóxicas o de acrilato, comúnmente, preferidas entre los productores.

Estas jornadas fueron parte de las diversas actividades extensionistas dedicadas a la comunidad de Los Órganos y Cabo Blanco que se realizaban en el seno del proyecto institucional. La alta abundancia de semilla detectada en los colectores y la riqueza de los bancos naturales, confirieron suficiente seguridad de utilizar esas 712 ostras (casi la mitad del stock en cultivo), en primer lugar, para promover la apropiación del proyecto; en segundo lugar, para identificar personas con aptitud quirúrgica que pudieran incorporarse al grupo de aprendices. En este contexto, actualmente, se cuenta con tres mujeres y un hombre reclutados de estas jornadas, quienes continuaron entrenando cirugía hasta la fecha en que la pandemia de la COVID-19 detuvo el trabajo.

Por dichas razones, en las prácticas de Mabe no siempre fue posible mantener control en que los protocolos se hicieran correctamente según las recomendaciones para $P$ t. sterna en cuanto al número y repartición de los medios-núcleos en las valvas (Monteforte et al., 1994; Ruíz-Rubio, Acosta-Salmón, Olivera, Southgate y Rangel-Dávalos, 2006; Jara et al., 2020). En esta práctica, participaron por lo menos doce personas con amplia mayoría de mujeres adultas y adolescentes. Sin embargo, los resultados con respecto al recubrimiento de nácar sirvieron para probar extremos, debido a que en ocasiones se encontraron hasta cuatro implantes en una u otra de las valvas (figura 4). De los 204 individuos reservados para cirugía de perla libre, se usó una veintena para que practicaran varios voluntarios, mujeres, en particular, y en el resto los técnicos de AgroMar del Pacífico continuaron su entrenamiento.
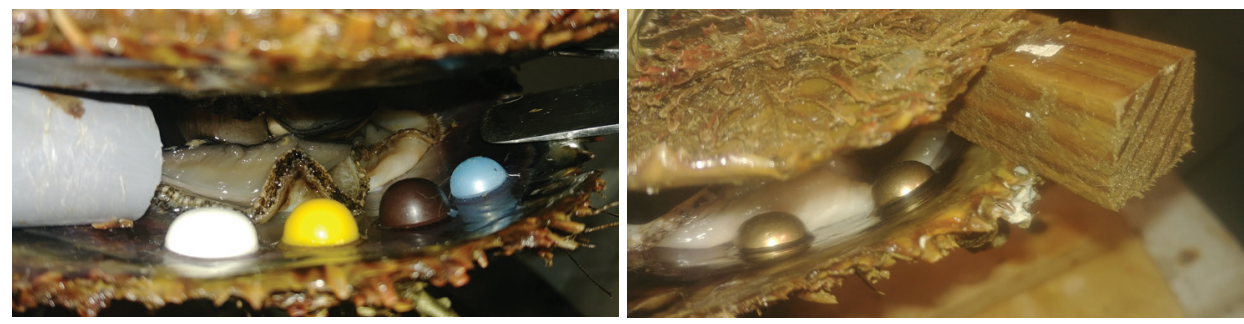

Figura 4. Muestra de implantes de media-perla en Pteria sterna realizados durante la jornada pública de perlicultura en Cabo Blanco. En las dos fotografías, el número de núcleos y su posicionamiento en la valva (cóncava y plana, respectivamente) no cumplen con las recomendaciones establecidas (ver texto)

Elaboración propia 
Los animales operados en esas jornadas se trasladaron al sistema de long-line en Los Órganos, dentro de sus respectivas redes de cartera, encerrando a los de perla libre en bolsas individuales de malla tipo mosquitero a fin de evaluar mortalidad y rechazos de núcleos. La costumbre entre las granjas perleras (de Pinctada spp.) es retirar estas bolsas al estabilizarse la mortalidad, igualando al estándar de los animales no operados, y esperar que no se detecten más rechazos (Alagarswami y Dharmaraj, 1984; Taylor y Strack, 2008). En ambos indicadores, esto ocurre dentro de las primeras 8-10 semanas poscirugía, y en Pt. sterna lo es para aprendices con buena aptitud que ya cuenten al menos con mil ensayos en su bitácora personal (Nava, Arizmendi, Farell y McLaurin, 2000).

\subsection{Análisis estadístico}

Para evaluar el perfil de la captación de semilla se aplicó un análisis de conteo por sitio (Los Órganos y Cabo Blanco), célula colectora (Netlon, en el primer sitio, y cebollera, en el segundo) y profundidad (2, 4 y 6 m). En la etapa de cultivo, se evaluó el crecimiento de la concha en función de tres grupos de talla: chica (20-40 mm), mediana (40-60 mm) y grande (70 $\mathrm{mm}$ y mayores), tomando como referencia la variación de altura promedio mensual de julio de 2017 a enero de 2018. Para el análisis estadístico del cultivo en linternas y en carteras, se evaluó el crecimiento de los individuos a dos densidades de siembra por grupo de tallas (tabla 1), mediante una prueba de ANOVA de dos vías con un nivel de confianza al $95 \%$, utilizando el programa estadístico Minitab 17. Previamente, se examinó la normalidad y homocedasticidad de varianzas con la prueba de residuales de Anderson-Darling disponible en dicho programa, la cual se basa en el ajuste a una distribución normal hipotética, que, en este caso, fue la t-Student. Así se determinó que los datos a analizar cumplían aceptablemente con los supuestos. Los factores con un efecto significativo $(p<0,05)$ se examinaron con pruebas de rango post-hoc de Tukey.

Tabla 1

Arreglo de las densidades de siembra de Pteria sterna en linternas y carteras por grupos de tallas

\begin{tabular}{ccccc}
\hline Grupo de tallas & \multicolumn{2}{c}{ Linterna } & \multicolumn{2}{c}{ Cartera } \\
\hline & \multicolumn{2}{c}{ Densidad (unidades/piso) } & \multicolumn{2}{c}{ Densidad (unidades/cartera) } \\
\cline { 2 - 5 } & $\mathrm{d} 1$ & $\mathrm{~d} 2$ & $\mathrm{~d} 1$ & $\mathrm{~d} 2$ \\
\hline Chica & 30 & 50 & 24 & 32 \\
Mediana & 20 & 40 & 15 & 18 \\
Grande & 10 & 20 & 6 & 12 \\
\hline
\end{tabular}

Elaboración propia

Con respecto a la perlicultura, tanto en los lotes de perla libre como en los de Mabe, se realizaron muestreos visuales de corto intervalo (conteo de muertos y rechazos), 
durante los dos primeros meses, postratamiento, y, luego, se alargaron a bimensual o trimestral, con sacrificio en cada muestreo (5-6 individuos al azar, en cada visita) y en octubre-noviembre de 2019 (11-12 meses, postratamiento, contando la permanencia en las artes de cultivo de $A$. purpuratus) se procedió a la cosecha. Las calificaciones de observación en las Mabe correspondientes a los muestreos y a la cosecha final se adjudicaron de manera descriptiva. Las ostras trabajadas con cirugía se sacrificaron en su totalidad al sexto mes, pues quedaban pocas supervivientes.

\section{RESULTADOS Y DISCUSIÓN}

\subsection{Vista general de las condiciones oceanográficas}

El comportamiento de la temperatura del agua durante el estudio mostró una situación particular derivada de las características de la región. En la figura 5, se observa que Los Órganos presentó temperaturas altas todos los meses, con un promedio de $22,57{ }^{\circ} \mathrm{C}$, en tanto que Cabo Blanco fue más frío, con un promedio de $19,11^{\circ} \mathrm{C}$. Este último sitio, se encuentra más expuesto a la corriente fría de Humboldt y también influye en la estratificación de las capas de agua. A este escenario se suma una temporada de El Niño que sucedió a principios de 2017 y la subsiguiente de La Niña durante el 2018.
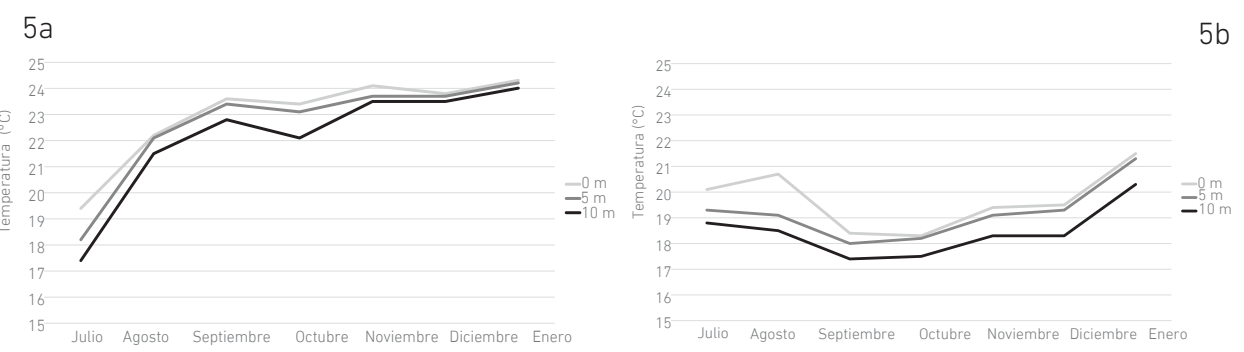

Figura 5. Variación de la temperatura mensual en Los Órganos (5a) y variación en Cabo Blanco (5b) durante el intervalo de tiempo en el presente estudio

Elaboración propia

\subsection{Captación de semilla}

La figura 6 presenta los resultados de la captación de semilla de Pt. sterna, durante la prueba experimental, con tiempo de inmersión de ochenta días, recordando que el estudio transcurrió durante la temporada posterior al evento de El Niño en el Perú y que, por lo tanto, hubo diferencias en el perfil de temperatura, entre los sitios de estudio, con valores diferentes hasta de $\pm 5{ }^{\circ} \mathrm{C}$ en los mismos meses (figura 5). El perfil de temperatura muestra que para los meses de captación (septiembre a noviembre) la temperatura 
promedio fue de $23,30^{\circ} \mathrm{C}$, en el primer sitio, y fue menor, registrando un promedio de $18,29^{\circ} \mathrm{C}$, para el segundo lugar.

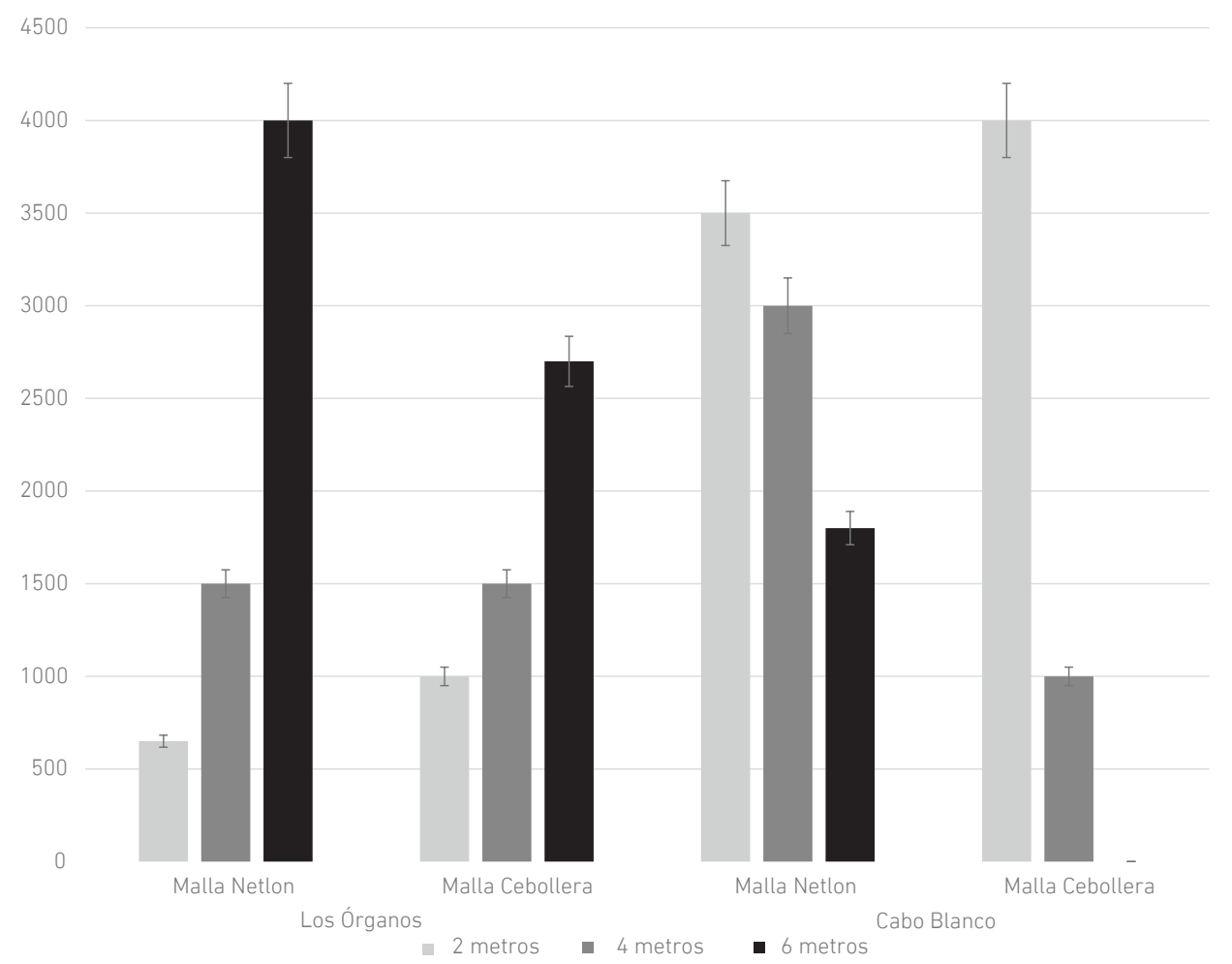

Figura 6. Conteo de semilla de Pteria sterna recuperada durante las secuencias de captación de semilla (septiembre-noviembre de 2017) en función de las variables probadas (tipo de colector, profundidad y sitio de estudio)

Elaboración propia

Se observó una suerte de imagen en espejo de la repartición vertical de la semilla al comparar Cabo Blanco y Los Órganos. En el primero, que se comportó como sitio frío, hubo tendencia de fijaciones a menor profundidad, en especial, la malla cebollera en ese sitio tuvo comparativamente poca captación a 4 y 6 m contra más de 4000 semillas a $2 \mathrm{~m}$. En Los Órganos, que fue el sitio cálido, ocurrió el caso contrario, con una preferencia por la cota de $6 \mathrm{~m}$ de profundidad y, en particular, por la malla Netlon, con captación relativamente menor a $2 \mathrm{~m}$ de profundidad. En términos generales, no se detectó que la semilla de Pt. sterna exhibiera preferencia por fijarse en costal cebollero o malla Netlon y tampoco que el tipo de colector tuviera relación con su repartición vertical, fuera esta de patrón frío o cálido. Las sumas de abundancia sugieren que el espacio frío de Cabo Blanco favoreció la eficiencia de la captación en ese sitio (figuras 5 y 6). Evidentemente, 
la interpretación de estos datos debe ser tomada con precaución debido a la diferencia de temperaturas y condiciones oceanográficas de Cabo Blanco y Los Órganos (figura 5).

Por otro lado, este estudio coincide con el intervalo del Niño/Niña de 2016-2018, que fue de efecto superior a lo moderado, en especial, hacia el Pacífico Sur. Al comparar el perfil de captación de Pt. sterna en el golfo de California (Monteforte, Kappelman-Piña y López-Espinosa, 1995), Acapulco (Torres-Zepeda, Morales-Salvador y Peralta-Montes, 2002) y Ecuador (Gregori et al., 2019) con los resultados en el Perú, los contrastes más notables residieron en la abundancia de semilla, aún en las temporadas de mayor captación, las cuales coinciden con temporadas frías en todos los casos. Es claro que la periodicidad estacional y/o la distribución vertical de la semilla pudieron variar debido a la ocurrencia de años del Niño y La Niña que afectan diferente al hemisferio norte y sur. Más aún, en bahía de La Paz, Saucedo y Monteforte (1997) reportan que la presencia de individuos maduros es continua todo el año, situando los principales desoves en la temporada fría (noviembre a febrero).

Asimismo, Cáceres Puig (2012) menciona que la especie desova, principalmente, en la temporada fría, ello explica la gran cantidad de semilla captada en Cabo Blanco, pues esta zona registró una temperatura promedio de $18,29{ }^{\circ} \mathrm{C}$, entre septiembre y noviembre. En Guaymas, los desoves ocurren en marzo-abril (Arizmendi-Castillo, 1996) y, por lo general, se colocan los colectores en ese período hasta el inicio de verano (junio-julio). En bahía de La Paz, las captaciones más abundantes se dan entre diciembre-enero y marzo (invierno-primavera), con marcada tendencia por profundidades superficiales por encima de 4-5 m, y si ocurre reclutamiento en verano, este es escaso y se distribuye por debajo de los $9-10 \mathrm{~m}$ de profundidad, hasta los $15 \mathrm{~m}$ probados por Monteforte et al. (1995).

Dicho patrón es similar en Guaymas (Arizmendi-Castillo, 1996) y Acapulco (TorresZepeda et al., 2002). En Ecuador, la mayor intensidad de reclutamiento sucede entre junio y agosto (temporada fría del sur), con preferencia por profundidades alrededor de $6 \mathrm{~m}$ (Gregori et al., 2019). Es evidente que las condiciones climáticas y otros factores que influyen en la cantidad de alimento disponible en el mar (temperatura, oxígeno, clorofila, minerales disueltos, dinámica de corrientes, estratificación, etc.) son determinantes en la tasa de reclutamiento de semilla natural y, por ende, en el rendimiento de los colectores. De todas maneras, es necesario estudiar con mayor detalle espacial y temporal el ciclo reproductivo y de reclutamiento de $P$ t. sterna en el Perú.

\subsection{Cultivo en campo por grupo de talla}

La densidad de individuos de Pt. sterna en las artes de cultivo tuvo un efecto diferente sobre el crecimiento (altura de la concha), dependiendo del grupo de talla (chica, mediana y grande) y/o el tipo de artefacto probado en cada sitio (linternas en Los Órganos y redes 
de cartera en Cabo Blanco) (tabla 1). En el primer sitio/artefacto, la prueba de ANOVA no detectó diferencias significativas en la talla final, entre densidades en el seno de cada grupo de talla $(F=1,95, p=0,124)$ y el esquema general de la tasa de crecimiento sugirió que esta habría sido más rápida en las linternas de Los Órganos que en las carteras de Cabo Blanco (tablas 2-4).

En efecto, en las ostras de talla chica, dentro de linternas en Los Órganos (tabla 2), se registró una ganancia en altura promedio de $7,56 \mathrm{~mm} / \mathrm{mes}$, para la densidad d1, y $8,68 \mathrm{~mm} / \mathrm{mes}$, para d2, con talla promedio final de $94,7 \pm 8,7 \mathrm{~mm}$ y $97,3 \pm 9,5 \mathrm{~mm}$, respectivamente; mientras que las de talla grande crecieron más lento, con una ganancia de $4,22 \mathrm{~mm} / \mathrm{mes}$, para d1, y $5,03 \mathrm{~mm} / \mathrm{mes}$, para $\mathrm{d} 2$, con talla promedio final de $130,7 \pm 8,4 \mathrm{~mm}$ y $130,6 \pm 7,4 \mathrm{~mm}$, respectivamente (tabla 4). Las ostras de talla mediana no presentaron diferencias significativas en la tasa de crecimiento, con respecto a los otros dos grupos y a sus propias densidades $(7,47 \mathrm{~mm} / \mathrm{mes}$ en d1 y $6,20 \mathrm{~mm} / \mathrm{mes}$ en $\mathrm{d} 2$, con talla promedio final de $124,9 \pm 5,1 \mathrm{~mm}$ y $122,5 \pm 5,9 \mathrm{~mm}$ ) (tabla 3). El desglose post-hoc de Tukey muestra que la tasa de crecimiento del grupo de talla chica fue, significativamente, mayor que en el grupo de las tallas mediana y grande, aunque el valor de confianza es relativamente bajo $(p=0,044)$, favoreciendo a la densidad de 50 unidades por piso (d2) (tabla 1).

\section{Tabla 2}

Biometría promedio mensual del grupo de talla chica de concha perlera Pteria sterna a dos diferentes densidades de siembra en linternas en Los Órganos

\begin{tabular}{lcccc} 
Talla chica & $\mathrm{d} 1$ (30 unidades por piso linterna) & $\mathrm{d} 2$ (50 unidades por piso linterna) \\
\hline Mes & $\begin{array}{c}\text { Altura promedio } \\
(\mathrm{mm})\end{array}$ & $\begin{array}{c}\text { Crecimiento } \\
\text { altura mensual } \\
(\mathrm{mm} / \mathrm{mes})\end{array}$ & $\begin{array}{c}\text { Altura promedio } \\
(\mathrm{mm})\end{array}$ & $\begin{array}{c}\text { Crecimiento altura } \\
\text { mensual (mm/mes) }\end{array}$ \\
\hline Julio & $50,0 \pm 9,1$ & $45,2 \pm 10,9$ & \\
Agosto & $60,0 \pm 8,5$ & 10,00 & $60,0 \pm 12,5$ & 74,80 \\
Septiembre & $72,5 \pm 8,8$ & 12,50 & $68,0 \pm 12,0$ & 7,98 \\
Octubre & $77,3 \pm 9,8$ & 4,63 & $75,7 \pm 9,5$ & 7,72 \\
Noviembre & $81,2 \pm 8,0$ & 4,70 & $79,6 \pm 9,0$ & 3,90 \\
Diciembre & $88,2 \pm 8,9$ & 7,00 & $87,3 \pm 9,2$ & 7,70 \\
Enero & $94,7 \pm 8,7$ & 6,50 & $97,3 \pm 9,5$ & 10,00 \\
\hline Promedio & & 7,56 & & 8,68 \\
\hline
\end{tabular}

Elaboración propia 
Tabla 3

Biometría promedio mensual del grupo de talla mediana de concha perlera Pteria sterna a dos diferentes densidades de siembra en linternas en Los Órganos

\begin{tabular}{lcccc}
\hline Talla mediana & $\mathrm{d} 1$ (20 unidades por piso linterna) & $\mathrm{d} 2$ (40 unidades por piso linterna) \\
\hline \multicolumn{1}{c}{ Mes } & $\begin{array}{c}\text { Altura promedio } \\
(\mathrm{mm})\end{array}$ & $\begin{array}{c}\text { Crecimiento altura } \\
\text { mensual }(\mathrm{mm} / \mathrm{mes})\end{array}$ & $\begin{array}{c}\text { Altura promedio } \\
(\mathrm{mm})\end{array}$ & $\begin{array}{c}\text { Crecimiento altura } \\
\text { mensual (mm/mes) }\end{array}$ \\
\hline Julio & $80,1 \pm 7,3$ & & $85,3 \pm 10,6$ & \\
Agosto & $94,0 \pm 11,0$ & 13,90 & $95,0 \pm 7,0$ & 9,70 \\
Septiembre & $98,0 \pm 7,8$ & 4,00 & $98,9 \pm 6,9$ & 3,90 \\
Octubre & $104,6 \pm 4,8$ & 6,60 & $103,7 \pm 5,8$ & 4,80 \\
Noviembre & $109,6 \pm 4,4$ & 5,00 & $108,3 \pm 5,1$ & 4,60 \\
Diciembre & $116,2 \pm 4,7$ & 6,60 & $113,4 \pm 5,9$ & 5,10 \\
Enero & $124,9 \pm 5,1$ & 8,70 & $122,5 \pm 5,9$ & 9,10 \\
\hline Promedio & & 7,47 & & 6,20 \\
\hline
\end{tabular}

Elaboración propia

Tabla 4

Biometría promedio mensual del grupo de talla grande de concha perlera Pteria sterna a dos diferentes densidades de siembra en linternas en Los Órganos

\begin{tabular}{lcccc}
\hline Talla grande & $\mathrm{d} 1$ (10 unidades por piso linterna) & $\mathrm{d} 2$ (20 unidades por piso linterna) \\
\hline Mes & $\begin{array}{c}\text { Altura promedio } \\
(\mathrm{mm})\end{array}$ & $\begin{array}{c}\text { Crecimiento altura } \\
\text { mensual }(\mathrm{mm} / \mathrm{mes})\end{array}$ & $\begin{array}{c}\text { Altura promedio } \\
(\mathrm{mm})\end{array}$ & $\begin{array}{c}\text { Crecimiento altura } \\
\text { mensual (mm/ } \\
\text { mes) }\end{array}$ \\
\hline Julio & $105,4 \pm 9,8$ & $100,4 \pm 7,5$ & \\
Agosto & $112,0 \pm 7,4$ & 6,60 & $108,0 \pm 8,8$ & 7,60 \\
Septiembre & $116,9 \pm 9,5$ & 4,90 & $113,4 \pm 8,3$ & 5,35 \\
Octubre & $117,1 \pm 8,0$ & 0,20 & $113,9 \pm 7,8$ & 0,55 \\
Noviembre & $120,0 \pm 8,1$ & 2,90 & $117,9 \pm 7,3$ & 4,00 \\
Diciembre & $123,3 \pm 8,4$ & 3,30 & $121,8 \pm 7,1$ & 3,90 \\
Enero & $130,7 \pm 8,4$ & 7,40 & $130,6 \pm 7,4$ & 8,80 \\
\hline Promedio & & 4,22 & & 5,03 \\
\hline
\end{tabular}

Elaboración propia

En las redes de cartera en Cabo Blanco, la densidad fue más influyente en el crecimiento comparado con las linternas en Los Órganos (tablas 5-7). En los tres grupos de talla, se detectaron diferencias significativas en altura promedio y/o tasa de crecimiento mensuales y finales, en función de la densidad de siembra. Así, en el grupo de talla chica, se registró una talla final de 75,9 $\pm 8,4 \mathrm{~mm}$ y ganancia promedio de 
$4,48 \mathrm{~mm} / \mathrm{mes}$, en la densidad d1, contra una talla final de $71,3 \pm 8,7 \mathrm{~mm}$ y ganancia promedio de 4,80 $\mathrm{mm} / \mathrm{mes,} \mathrm{en} \mathrm{la} \mathrm{densidad} \mathrm{d2} \mathrm{(tabla} \mathrm{5)}(F=11,34, p=0,001$ ). Para el grupo de talla mediana, en la densidad d1, se registró una talla promedio final de $109,9 \pm 8,2 \mathrm{~mm}$ con crecimiento promedio mensual de $5,20 \mathrm{~mm}$, en la densidad d2, una talla final de $100,6 \pm 8,9 \mathrm{~mm}$ que crecieron un promedio de $4,92 \mathrm{~mm} / \mathrm{mes}$ (tabla 6 ) $(F=15,97, p=0,000)$. Finalmente, en el grupo de talla grande, bajo la densidad d1, se registró una talla promedio final de $128,6 \pm 6,6 \mathrm{~mm}$ y crecimiento mensual de $3,83 \mathrm{~mm} / \mathrm{mes}$, y, en la densidad d2, la talla promedio final fue de $124,4 \pm 6,7 \mathrm{~mm}$ con tasa de crecimiento promedio de 4,10 mm (tabla 7$)(F=4,4, p=0,045)$. El desglose post-hoc de Tukey parece favorecer a las densidades menores con valores de $p$ entre 0,03 (talla grande) y 0,004 (talla chica). Sin embargo, en el comparativo de conjuntos, respecto a las linternas de Los Órganos, los indicadores de talla y crecimiento en las carteras de Cabo Blanco mostraron inclinación a ser menores en los tres grupos de talla, en particular, el de las chicas que, en las linternas, los indicadores están casi al doble valor de los iniciales respectivos (tablas 2 y 5 ).

Tabla 5

Biometría promedio mensual del grupo de talla chica de concha perlera Pteria sterna a dos diferentes densidades de siembra en carteras en Cabo Blanco

\begin{tabular}{lcccc}
\hline Talla chica & \multicolumn{2}{c}{ d1 (24 unidades por cartera) } & d2 (32 unidades por cartera) \\
\hline \multicolumn{1}{c}{ Mes } & $\begin{array}{c}\text { Altura promedio } \\
(\mathrm{mm})\end{array}$ & $\begin{array}{c}\text { Crecimiento altura } \\
\text { mensual (mm/mes) }\end{array}$ & $\begin{array}{c}\text { Altura promedio } \\
(\mathrm{mm})\end{array}$ & $\begin{array}{c}\text { Crecimiento altura } \\
\text { mensual (mm/mes) }\end{array}$ \\
\hline Julio & $51,3 \pm 8,2$ & $44,1 \pm 8,5$ & \\
Agosto & $51,3 \pm 7,7$ & 0,00 & $46,1 \pm 9,6$ & 2,00 \\
Septiembre & $56,1 \pm 7,6$ & 4,80 & $49,5 \pm 8,0$ & 3,40 \\
Octubre & $65,0 \pm 8,8$ & 8,90 & $59,2 \pm 9,3$ & 9,70 \\
Noviembre & $69,4 \pm 8,3$ & 4,40 & $60,4 \pm 9,0$ & 1,20 \\
Diciembre & $73,7 \pm 8,6$ & 4,30 & $68,3 \pm 8,5$ & 7,90 \\
Enero & $75,9 \pm 8,4$ & 2,20 & $71,3 \pm 8,7$ & 3,00 \\
\hline Promedio & & 4,48 & & 4,80 \\
\hline
\end{tabular}

Elaboración propia 
Tabla 6

Biometría promedio mensual del grupo de talla mediana de concha perlera Pteria sterna a dos diferentes densidades de siembra en carteras en Cabo Blanco

\begin{tabular}{lcccc}
\hline Talla mediana & \multicolumn{1}{c}{$\mathrm{d} 1$ (15 unidades por cartera) } & $\mathrm{d} 2$ (18 unidades por cartera) \\
\hline Mes & $\begin{array}{c}\text { Altura promedio } \\
(\mathrm{mm})\end{array}$ & $\begin{array}{c}\text { Crecimiento altura } \\
\text { mensual }(\mathrm{mm} / \mathrm{mes})\end{array}$ & $\begin{array}{c}\text { Altura promedio } \\
(\mathrm{mm})\end{array}$ & $\begin{array}{c}\text { Crecimiento altura } \\
\text { mensual }(\mathrm{mm} / \mathrm{mes})\end{array}$ \\
\hline Julio & $78,6 \pm 7,2$ & $71,1 \pm 7,6$ & \\
Agosto & $84,6 \pm 6,2$ & 6,00 & $77,1 \pm 6,7$ & 6,00 \\
Septiembre & $91,6 \pm 8,9$ & 7,00 & $82,8 \pm 8,7$ & 5,70 \\
Octubre & $95,5 \pm 8,2$ & 3,90 & $86,1 \pm 9,1$ & 3,30 \\
Noviembre & $99,7 \pm 8,3$ & 4,20 & $90,5 \pm 9,4$ & 4,40 \\
Diciembre & $104,7 \pm 8,2$ & 5,00 & $94,9 \pm 8,8$ & 4,40 \\
Enero & $109,9 \pm 8,2$ & 5,20 & $100,6 \pm 8,9$ & 5,70 \\
\hline Promedio & 5,22 & & 4,92 \\
\hline
\end{tabular}

Elaboración propia

Tabla 7

Biometría promedio mensual del grupo de talla grande de concha perlera Pteria sterna a dos diferentes densidades de siembra en carteras en Cabo Blanco

\begin{tabular}{lcccc}
\hline Talla grande & \multicolumn{2}{c}{$\mathrm{d} 1$ (6 unidades por cartera) } & \multicolumn{2}{c}{$\mathrm{d} 2$ (12 unidades por cartera) } \\
\hline \multicolumn{1}{c}{ Mes } & $\begin{array}{c}\text { Altura promedio } \\
(\mathrm{mm})\end{array}$ & $\begin{array}{c}\text { Crecimiento altura } \\
\text { mensual }(\mathrm{mm} / \mathrm{mes})\end{array}$ & $\begin{array}{c}\text { Altura promedio } \\
(\mathrm{mm})\end{array}$ & $\begin{array}{c}\text { Crecimiento altura } \\
\text { mensual (mm/mes) }\end{array}$ \\
\hline Julio & $105,7 \pm 10,6$ & $99,8 \pm 9,5$ & \\
Agosto & $109,5 \pm 12,1$ & 3,80 & $104,2 \pm 6,7$ & 4,40 \\
Septiembre & $117,2 \pm 18,7$ & 7,70 & $111,9 \pm 10,8$ & 7,70 \\
Octubre & $118,3 \pm 5,9$ & 1,10 & $112,2 \pm 6,9$ & 0,30 \\
Noviembre & $120,8 \pm 5,0$ & 2,50 & $116,0 \pm 5,9$ & 3,80 \\
Diciembre & $124,8 \pm 5,4$ & 4,10 & $119,6 \pm 6,5$ & 3,60 \\
Enero & $128,6 \pm 6,6$ & 3,80 & $124,4 \pm 6,7$ & 4,80 \\
\hline Promedio & & 3,83 & 4,10 \\
\hline
\end{tabular}

Elaboración propia

Para comparar estos resultados con otros trabajos sobre crecimiento de Pt. sterna en condiciones de cultivo, se cuenta con datos en bahía de Los Ángeles (VoltolinaLobina, Buckle-Ramírez, Morales y Valenzuela, 1992), La Paz (Monteforte, 2013a) y Ecuador (Lodeiros et al., 2018), pero los espacios geográficos y las temporadas en que se llevaron a cabo estos estudios son diferentes en cuanto a condiciones oceanográficas. En 
particular, durante la época en que se realizó el presente trabajo ocurrió un evento de El Niño de alta intensidad seguido de un La Niña relativamente moderado.

Los Órganos y Cabo Blanco presentaron regímenes diferentes de temperatura (figura 5), con lo cual la interpretación de contrastes en el crecimiento de Pt. Sterna, entre ambos sitios, debe ser tomada con precaución como en el caso de la captación de semilla. Sin embargo, pareciera que el común denominador es que la especie responde mejor durante la temporada fría, por lo que el crecimiento en carteras en Cabo Blanco tuvo tendencia a ser más rápido que en linternas en Los Órganos para todos los grupos de talla y las densidades probadas. En términos generales, todo parece indicar que $P t$. sterna habría presentado una tasa de crecimiento más rápida y tallas mayores en el Perú que en los sitios estudiados en Ecuador y México, a reserva de ser examinado durante un año "normal".

Según Ruíz-Rubio et al. (2006), Pt. sterna es la ostra perlera más pequeña usada en la producción comercial de Mabe. Los estudios en torno a la respuesta de Pt. sterna bajo operaciones de implante o cirugía (La Paz, Guaymas, Acapulco y Ecuador) coinciden en señalar que la talla mínima de altura de la concha debe ser 75-80 mm, como lo especifica la normativa establecida en México para esta especie (Secretaría de Agricultura, Ganadería, Desarrollo Rural, Pesca y Alimentación, 2013). Sin embargo, hay diferencias en cuanto al tiempo en cultivo para llegar a ese estándar dependiendo de las regiones. En La Paz, Guaymas y Acapulco oscila entre 15 y 18 meses (Kiefert, McLaurin Moreno, Arizmendi, Hänni y Elen, 2004; Monteforte, 2013b; Serna-Gallo et al., 2014), en tanto que Lodeiros et al. (2018) para Ecuador reportan esa talla estándar en menos de un año con cultivo en artefactos tipo cartera, y hasta $100 \mathrm{~mm}$ en 12-14 meses.

En el presente trabajo, se encontró que respecto al Pt. Sterna cultivada durante 10-11 meses, la gran mayoría de individuos en los grupos de talla mediana y grande sobrepasaba $100 \mathrm{~mm}$ de altura de la concha, notándose mejor crecimiento en las carteras, aunque no excesivamente significativo ( $p=0,048$ ) (tablas $2-7$ ), pero sí en cuanto a la regularidad en la forma de la concha con respecto a los individuos desordenados en las linternas.

\subsection{Resultados y comentarios de la perlicultura}

Como se explicó con antelación, el propósito del proyecto en esta ocasión se dirigió a construir los principales bloques sociales en la región objetivo en torno al modelo de granja perlera con Pt. sterna. El seguimiento de los 508 implantados con media-perla permitió apreciar la buena calidad en el recubrimiento de nácar de manera que, en el muestreo de cosecha (unos 200 individuos en total, todos con al menos una pieza de Mabe), se obtuvieron casi 250 Mabe de calidad buena a muy buena, hasta unas 5 o 6 que fueron joyas (figura 7), a pesar de que pocos casos cumplieron con la repartición 2:1 o 2:2, 
recomendada para la especie, y también con la colocación de los implantes (Monteforte et al., 1994; Ruíz-Rubio et al., 2006; Jara et al., 2020). En la figura 7 se presentan los resultados de algunos muestreos, notando que la cromática del nácar se asemeja al patrón general de la especie.

La mortalidad de este lote llegó al punto de inflexión en el mes 4, con un acumulado del $35 \%$ contra menos del $10 \%$ en animales no operados. Suponemos toxicidad debido a la volatilidad del pegamento y/o anestésico incorrecto, pues la mortalidad fue aguda desde la primera semana postratamiento. De allí en adelante ambos lotes mantuvieron una supervivencia del $95 \%$ hasta octubre de 2019 cuando se levantó la cosecha (figura 7). Por el contrario, la mortalidad poscirugía de perla libre llegó al $75 \%$ en el mes 4. Del restante $25 \%$ (51 supervivientes), casi la mitad había rechazado su respectivo núcleo durante los primeros dos meses poscirugía. El sacrificio de estos animales reveló que algunos núcleos estaban descolocados del punto correcto de inoculación y sin cubrimiento, otros se encontraron sueltos fuera de la masa visceral (sin expulsión definitiva), y en ningún caso hubo indicios de granos de nácar (Keshi), que se forman a partir del injerto (el trozo de manto, o saibo, como lo nombran algunos autores) cuando el núcleo ha sido rechazado.

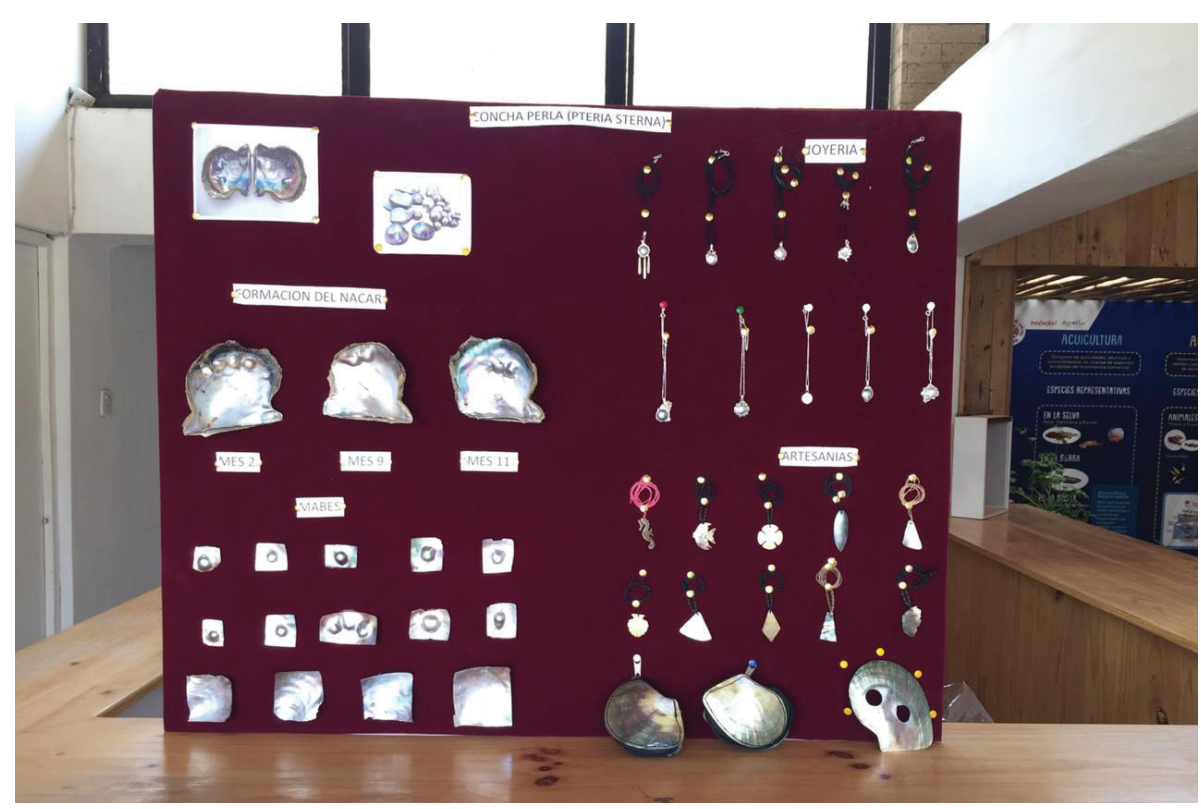

Figura 7. Resultados de piezas de artesanía local en concha. En la parte izquierda del panel nótense las tres conchas de Pt. sterna, una de ellas con cuatro núcleos, y el corte de Mabe en la segunda hilera con tres núcleos

Elaboración propia 
Al final de la línea, el proyecto está generando un ejemplo de éxito en el Perú, lo cual se ha concretado en una empresa comunitaria denominada Perlas del Mar de Cabo Blanco, con su grupo de perlicultura bien definido. Esto ha permitido la puesta en obra de experimentos encaminados a afinar las técnicas de implante y cirugía. En adición, los datos generados en este trabajo vienen a enriquecer y ampliar geográficamente el conocimiento sobre Pt. sterna.

\section{CONCLUSIONES Y RECOMENDACIONES}

- La oceanografía del mar costero en la región de estudio es determinante en el perfil poblacional de Pteria sterna y su respuesta al manejo en condiciones de cultivo extensivo. Un fenómeno de ecotono, combinado con influencias de eventos ENSO, dio lugar a que Los Órganos y Cabo Blanco se comportaran como la zona de transición que ocurre en la región marina-costera al noroeste de México.

- El rendimiento de captación sobrepasó expectativas, con un total de 24250 semillas cosechadas. Los conteos de hasta 1500 unidades o más por célula colectora fueron frecuentes en condiciones de pico (figura 6). Los resultados sugieren una preferencia por el mismo tipo de células colectoras utilizadas en las granjas de concha abanico, A. purpuratus (sustrato de malla Netlon azul, embolsado en nailon verde 1,5 mm de luz). En la repartición vertical se notó tendencia por mayor profundidad en condiciones cálidas (Los Órganos) y hacia la superficie en condiciones frías (Cabo Blanco), y por una mayor abundancia comparativa en condiciones frías (figura 6). Esto parece coincidir con lo conocido en México y Ecuador.

- Los resultados de crecimiento y supervivencia de individuos de Pt. sterna recolectados en las granjas de concha abanico mostraron tendencia a mejores indicadores en las linternas de Los Órganos que en las carteras de Cabo Blanco. En el primer sitio, el efecto de densidad tuvo poca influencia en la respuesta de los tres grupos de talla; mientras que, en el segundo, a menor densidad en conjunto se notó mejor crecimiento y tallas grandes en los tres grupos de talla, particularmente, en el de las chicas. Este patrón no es conclusivo debido al escenario general propio a cada sitio.

- Los resultados de la perlicultura demostraron la amplia factibilidad técnica y el valor en la formación de recursos humanos en comunidades vulnerables.

- Se recomienda continuar con los estudios sistematizados apuntando a afinar el manejo del cultivo extensivo en las condiciones del Perú, así como las técnicas de perlicultura cuando el estado de pandemia por la COVID-19 lo permita. 


\section{REFERENCIAS}

AgroMar del Pacífico (2018). Crianza experimental de concha perlera - Tercera experiencia. Fortalecimiento de capacidades para mejorar las condiciones operativas productivas en la actividad pesquera-acuícola artesanal en las provincias de Talara, Paita y Sechura. Reporte del proyecto SNIP 162711. Gobierno Regional de Piura.

Alagarswami, K., y Dharmaraj, S. (1984). Manual of Pearl Culture Techniques. CMFRI Special Publication, 20, 1-42.

Álamo, V., y Valdivieso, V. (1997). Lista sistemática de moluscos marinos del Perú (2. a ed.). Callao, Perú: Instituto del Mar del Perú.

Arizmendi-Castillo, E. (1996). Ciclo reproductivo de las ostras perleras, Pinctada mazatlanica (Hanley, 1856) y Pteria sterna (Gould, 1851), (Pteriidae), en el área de Guaymas, Sonora, México (tesis de maestría). Instituto Tecnológico y de Estudios Superiores de Monterrey-Guaymas, México.

Baudin, L. (1961). A socialist empire. The Incas of Peru. Princeton, New Jersey: D. Van Nostrand Co. Ltd.

Cáceres Puig, J. I. (2012). Dinámica del Reclutamiento de Juveniles de Concha Nácar Pteria sterna en la bahía de La Paz, Baja California Sur, México (tesis doctoral). Centro de Investigaciones Biológicas del Noreste, México. Recuperada de http://cibnor. repositorioinstitucional.mx/jspui/handle/1001/193

Cipriani, R., Guzmán, H. M., y López, M. (2008). Harvest history and current densities of the pearl oyster Pinctada mazatlanica (Bivalvia: Pteriidae) in Las Perlas and Coiba Archipelagos, Panama. Journal of Shellfish Research, 27(4), 691-700. https://doi. org/10.2983/0730-8000(2008)27[691:hhacdo]2.0.co

Echevin, V., Aumont, O., Ledesma, J., y Flores, G. (2008). The seasonal cycle of surface chlorophyll in the Peruvian upwelling system: A modelling study. Progress in Oceanography, 79(2-4), 167-176.

Flores-Ysla, F. E., Rojas-Hurtado, D., y Fernandini, F. (27 de septiembre de 2017). Cultivo de concha perlera en sistema suspendido en Los Órganos y Cabo Blanco. Jornada Acuícola Internacional, Piura, Perú.

Freites, L., Franklin, J., Gregori, M., Márquez, A., Saucedo, P. E., y Lodeiros, C. (2020). Performance of the winged pearl oyster Pteria sterna (Gould, 1851), implanted for half-pearl (Mabe) production in two size groups. Aquaculture, 524. https://doi. org/10.1016/j.aquaculture.2020.735267

Google Earth (2016). Zona de Los Órganos y Zona de Cabo Blanco. Piura, Perú. 
Granados-Amores, A., Saucedo, P. E., Mazón-Suástegui, J. M., Rodríguez-Jaramillo, C., Acosta-Salmón, H., Zenteno-Savin, T., y Campa-Córdova, Á. I. (2018). Does relaxation as a sedative therapy previous to pearl production affect antioxidant response and cause oxidative damage in the winged pearl oyster Pteria sterna? Aquaculture, 491, 295-301. https://doi.org/10.1016/j.aquaculture.2018.03.051

Gregori, M., Villón, J., Jara, F., Gonzabay-Tomalá, P., y Freites, L. (2019). Spatial and temporal spatfall of the winged pearl oyster Pteria sterna (Gould, 1851) in Equatorial Coasts. Aquaculture, 511, 734258. https://doi.org/10.1016/j. aquaculture.2019.734258

Haws, M. C., Ellis, C. S., y Ellis, P. E. (2006). Producing half-pearls (Mabe). Western Indian Ocean Marine Science Association, University of Dares es Salaam, University of Hawaii, Hilo and the Coastal Resources Center, University of Rhode Island,

Jara, F., Gregori, M., Rodríguez-Pesantes, D., Freites, L., Lodeiros, C., y Márquez, A. (2020). Efecto del tamaño del núcleo en la calidad de las medias perlas (Mabe) producidas por la ostra alada Pteria sterna (Gould, 1851) en costas ecuatorianas. XXII Foro dos Recursos Mariños e da Acuicultura das Rías Galegas, 361-367.

Johnston, W. L., Hine, D., y Southgate, P. C. (2018). Economic modeling of round pearl culture in Fiji and assessment of viable farm size. Journal of Shellfish Research, 37(1), 79-91.

Keen, M. (1971). Sea shells of tropical west America: marine mollusks from Baja California to Peru (2. ${ }^{\text {a }}$ ed.). Stanford, California: Stanford University Press.

Kiefert, L., McLaurin Moreno, D., Arizmendi, E., Hänni, H. A., y Elen, S. (2004). Cultured pearls from the Gulf of California, Mexico. Gems and Gemology, 40(1), 26-38. doi:10.5741/GEMS.40.1.26

Lluch-Belda, D. (2000). Centros de actividad biológica en la costa occidental de Baja California. En D. Lluch-Belda, J. Elorduy-Garay, S. E. Lluch-Cota, y G. PonceDíaz (Eds.), BAC, Centros de actividad biológica en el Pacífico mexicano (pp. 49-64). México: Centro de Investigaciones Biológicas del Noroeste.

Lodeiros, C., Rodríguez-Pesantes, D., Márquez, A., Revilla, J., Freites, L., LodeirosChacón, C., y Sonnenholzner, S. (2018). Growth and survival of the winged pearl oyster Pteria sterna (Gould, 1851) in suspended culture in the tropical Eastern Pacific: Influence of environmental factors. Aquaculture Research, 49(2), 832-838. https://doi.org/10.1111/are.13514

Luque Sánchez, C., Solís Acosta, J., Morón Antonio, O., y Crispín Carpio, M. (2001). Prospección de la concha perlífera Pteria sterna en Talara, noviembre 2000. Informe Progresivo Instituto del Mar de Perú, (154). 
Monteforte, M. (2013a). Evolución de la perlicultura: Sinopsis gráfica comentada de una tecnología milenaria. XIII Congreso de la Asociación de Investigadores del Mar de Cortes (AIMAC). Ensenada BC, México. doi:10.13140/RG.2.2.34875.67367

Monteforte, M. (2013b). Instalación y operación de granjas perleras. Un manual para Pinctada mazatlanica y Pteria sterna. Editorial Académica Española.

Monteforte, M., y Cariño, M. (2013). Condiciones para el desarrollo de granjas perleras y producción de perlas: estado del arte, potencial y perspectivas. Revista de Biología Marina y Oceanografía, 48(1), 1-16. http://dx.doi.org/10.4067/S071819572013000100001

Monteforte, M., y Cariño, M. (en prensa). Apuntes para la historia de la acuacultura en el golfo de California. En M. Cariño y W. Domínguez (Eds.), Nuestro mar (vol. II, Extractivismo industrial y comercial del golfo de California) (pp. 175-224). Universidad de Granada, España/Consejo Nacional de Ciencia y Tecnología, México.

Monteforte, M., Bervera, H., Morales, S., Pérez, V., Saucedo, P., y Wright, H. (1994). Results on the production of cultured pearls in Pinctada mazatlanica and Pteria sterna from bahía de La Paz, South Baja California, México. Journal of Shellfish Research, 13(1), 344-345.

Monteforte, M., Kappelman-Piña, E., y López-Espinosa, B. (1995). Spatfall of pearl oyster, Pteria sterna (Gould), on experimental collectors at bahía de La Paz, South Baja California, Mexico. Aquaculture Research, 26(7), 497-511. https://doi. org/10.1111/j.1365-2109.1995.tb00940.x

Morón Antonio, O., y Tenorio, J. (2011). Aspectos oceanográficos en primavera 2003: Crucero bento-demersal BIC Humboldt 0310. Informe del Instituto del Mar Perú, 38(1), 75-80.

Murphy, R. C. (1923). Fisheries resources in Peru. The Scientific Monthly, 16(6), 594-607.

Nava, M., Arizmendi, E., Farell, S., y McLaurin, D. (2000). Evaluation of success in the seeding of round nuclei in Pteria sterna (Gould 1851), a new species in pearl culture. SPC Pearl Oyster Information Bulletin, 14, 12-16.

Ordinola, E., Alemán, S., y Vera, M. (2013). Características biológicas de una población de Pteria sterna (Bivalvia: Pteriidae) en Zorritos, Tumbes, Perú. Revista Peruana de Biología, 20(2), 181-186.

Ordinola, E., Montero, P., Alemán, S., Argüelles, J., Beltrán, L., y Llanos J. (2010). El bivalvo concho perlífera, Pteria sterna (Gould), en Talara, Perú. Abril 2007. Instituto del Mar del Perú. Perú, 37(3-4), 127-137. 
Organización de las Naciones Unidas para la Alimentación y la Agricultura. (2020). The State of the World Fisheries and Aquaculture. Sustainability in action. The State of the World Series. Roma. Recuperado de http://www.fao.org/3/ca9229en/ ca9229en.pdf

Paredes, C., Tarazona, J., Canahuire, E., Romero, L., Cornejo, O., y Cardoso, F. (1998). Presencia de moluscos tropicales de la provincia panameña en la costa central del Perú y su relación con los eventos “El Niño". Revista Peruana de Biología, 5(2), 123-128.

Ramírez-Gastón, J., Sandoval-Méndez, N., y Vicente-Cárdenas, K. (2018). Sistema Nacional de Innovación en Pesca y Acuicultura. Fundamentos y propuesta 20172022. Serie Estudios Preinversión 3. Programa Nacional de Innovación en Pesca y Acuicultura, Ministerio de la Producción. Perú.

Ruíz-Rubio, H., Acosta-Salmón, H., Olivera, A., Southgate, P. C., y Rangel-Dávalos, C. (2006). The influence of culture method and culture period on quality of half-pearls ('mabé') from the winged pearl oyster Pteria sterna, Gould, 1851. Aquaculture, 254(1), 269-274.

Saucedo, P., y Monteforte, M. (1997). Breeding cycle of pearl oysters Pinctada mazatlanica and Pteria sterna (Bivalvia: Pteriidae) at Bahia de La Paz, Baja California Sur, Mexico. Journal of Shellfish Research, 16(1), 103-110.

Secretaría de Agricultura, Ganadería, Desarrollo Rural, Pesca y Alimentación. (2013). Norma Oficial Mexicana NOM-058-SAGg/PESC/SEMARNAT-2013 para regular el cultivo de las ostras perleras: madreperla (Pinctada mazatlanica), concha nácar (Pteria sterna), madreperla del atlántico (Pinctada imbricata) y la ostra perlera alada del atlántico (Pteria colymbus) en aguas marinas de jurisdicción federal de los Estados Unidos Mexicanos. Recuperada de http://www.dof.gob.mx/ normasOficiales/5276/sagarpa11_C/sagarpa11_C.html

Serna-Gallo, I., Ruíz-Velazco, J. M., Acosta-Salmón, H., Peña-Messina, E., TorresZepeda, G., y Saucedo, P. E. (2014). Patrones de crecimiento y reproducción de la concha nácar, Pteria sterna, cultivada en un ambiente tropical de México: Implicaciones para el cultivo de perlas. Ciencias Marinas, 40(2), 75-88. https:// doi.org/10.7773/cm.v40i2.2393

Solano López, Y., Cabrera Peña, J., Cruz, R. A., y Palacios, J. A. (1997b). Estructura de la población y crecimiento de Pinctada mazatlanica (Pterioida: Pteriidae), golfo de Nicoya, Costa Rica. Revista de Biología Tropical, 45(3), 1055-1060.

Solano López, Y., Cabrera Peña, J., Palacios, J. A., y Cruz, R. A. (1997a). Madurez sexual, índice de condición y rendimiento de Pinctada mazatlanica (Pterioida: Pteriidae), golfo de Nicoya, Costa Rica. Revista de Biología Tropical, 45(3): 1049-1054. 
Solano López, Y., Cabrera Peña, J., Protti Quesada, M., y Cruz Soto, R. (1995). Relaciones morfométricas de Pinctada mazatlanica (Bivalvia: Pteriidae) en Puntarenas, Costa Rica. Revista de Biología Tropical, 43(1-3), 177-180.

Southgate, P. C. (2008). Pearl oyster culture. En P. C. Southgate y J. S. Lucas (Eds.), The pearl oyster (pp. 231-272). Elsevier Science.

Swartzman, G., Bertrand, A., Gutiérrez, M., Bertrand, S., y Vásquez, L. (2008). The relationship of anchovy and sardine to water masses in the Peruvian Humboldt Current System from 1983 to 2005. Progress in Oceanography, 79(2-4), 228-237. doi:10.1016/j.pocean.2008.10.021

Taylor, J., y Strack, E. (2008). Pearl production. En P. C. Southgate y J. S. Lucas (Eds.), The pearl oyster (pp. 273-302). Elsevier Science.

Torres-Zepeda, M. G., Morales-Salvador, J., y Peralta-Montes, L. (2002). Evaluación de la captación estacional y batimétrica de semilla de la madreperla Pinctada mazatlanica (Hanley 1856) y la concha nácar Pteria sterna (Gould 1851) en colectores artificiales en la bahía de Acapulco (Guerrero, México). Memorias del Congreso Iberoamericano Virtual de Acuicultura CIVA 2002.

Treviño Zambrano, L. M. (2018). Acondicionamiento gonádico e inducción al desove por "shock" térmico en la ostra perlífera Pteria sterna (Gould, 1851) en condiciones de laboratorio (tesis de maestría). Universidad Nacional Agraria La Molina.

Vergara, O., Dewitte, B., Montes Torres, I., Garçon, V., Ramos, M., Paulmier, A., y Pizarro, O. (2016). Seasonal variability of the oxygen minimum zone off Peru in a highresolution regional coupled model. Biogeosciences, 13(15), 4389-4410. https:// doi.org/10.5194/bg-13-4389-2016

Voltolina-Lobina, D., Buckle-Ramírez, L. F., Morales, E., y Valenzuela, B. F. (1992). Spat settlement and growth of Pteria sterna (Gould) (mollusca, bivalvia) in Bahia de Los Angeles, Baja California, México. Tropical Ecology, 33(2), 137-147. 